\title{
Curcumin limits the fibrogenic evolution of experimental steatohepatitis
}

\author{
Francesco Vizzutti ${ }^{1,5}$, Angela Provenzano ${ }^{1,5}$, Sara Galastri ${ }^{1}$, Stefano Milani ${ }^{2,3}$, Wanda Delogu ${ }^{1}$, Erica Novo ${ }^{4}$, \\ Alessandra Caligiuri ${ }^{1}$, Elena Zamara ${ }^{4}$, Umberto Arena ${ }^{1}$, Giacomo Laffi ${ }^{1}$, Maurizio Parola ${ }^{4}$, Massimo Pinzani ${ }^{1,3}$ \\ and Fabio Marra ${ }^{1,3}$
}

Nonalcoholic steatohepatitis is characterized by the association of steatosis with hepatic cell injury, lobular inflammation and fibrosis. Curcumin is known for its antioxidant, anti-inflammatory and antifibrotic properties. The aim of this study was to test whether the administration of curcumin limits fibrogenic evolution in a murine model of nonalcoholic steatohepatitis. Male C57BL/6 mice were divided into four groups and fed a diet deficient in methionine and choline (MCD) or the same diet supplemented with methionine and choline for as long as 10 weeks. Curcumin ( $25 \mu \mathrm{g}$ per mouse) or its vehicle (DMSO) was administered intraperitoneally every other day. Fibrosis was assessed by Sirius red staining and histomorphometry. Intrahepatic gene expression was measured by quantitative PCR. Hepatic oxidative stress was evaluated by staining for 8-OH deoxyguanosine. Myofibroblastic hepatic stellate cells (HSCs) were isolated from normal human liver tissue. The increase in serum ALT caused by the MCD diet was significantly reduced by curcumin after 4 weeks. Administration of the MCD diet was associated with histological steatosis and necro-inflammation, and this latter was significantly reduced in mice receiving curcumin. Curcumin also inhibited the generation of hepatic oxidative stress. Fibrosis was evident after 8 or 10 weeks of MCD diet and was also significantly reduced by curcumin. Curcumin decreased the intrahepatic gene expression of monocyte chemoattractant protein-1, CD11b, procollagen type I and tissue inhibitor of metalloprotease (TIMP)-1, together with protein levels of $\alpha$-smooth muscle-actin, a marker of fibrogenic cells. In addition, curcumin reduced the generation of reactive oxygen species in cultured HSCs and inhibited the secretion of TIMP-1 both in basal conditions and after the induction of oxidative stress. In conclusion, curcumin administration effectively limits the development and progression of fibrosis in mice with experimental steatohepatitis, and reduces TIMP-1 secretion and oxidative stress in cultured stellate cells.

Laboratory Investigation (2010) 90, 104-115; doi:10.1038/labinvest.2009.112; published online 9 November 2009

KEYWORDS: curcumin; fibrosis; hepatic stellate cells; nonalcoholic steatohepatitis; tissue inhibitor of metalloprotease-1

Nonalcoholic fatty liver disease (NAFLD) is one of the most frequent causes of liver dysfunction in Western countries. ${ }^{1}$ Obesity and insulin resistance are major risk factors for the development of NAFLD, which is considered the hepatic manifestation of metabolic syndrome. Accordingly, the prevalence of NAFLD has increased markedly, along with the acquisition of a sedentary lifestyle and changes in dietary habits. NAFLD comprises 'simple' fatty liver, a condition believed to bear little risk of progression, and nonalcoholic steatohepatitis (NASH), that may lead to progressive liver disease, including cirrhosis and its complications, and hepatocellular carcinoma. ${ }^{2-4}$ In comparison with bland stea- tosis, NASH is histologically similar to alcoholic steatohepatitis, and is characterized by the presence of signs of hepatocellular damage and inflammation, including ballooning degeneration and hepatocyte death, formation of Mallory-Denk bodies, and infiltration with inflammatory cells. ${ }^{5}$ These changes are associated with a variable degree of fibrosis or with the presence of cirrhosis. ${ }^{5,6}$ Although several aspects in the pathogenesis of NASH remain unclear, it is now well established that accumulation of excess lipids, especially in the form of free fatty acids, results in toxic damage to the hepatocytes, or lipotoxicity, which triggers inflammation and tissue repair in the form of fibrosis. ${ }^{7,8}$ In

\footnotetext{
${ }^{1}$ Dipartimento di Medicina Interna, University of Florence, Florence, Italy; ${ }^{2}$ Dipartimento di Fisiopatologia Clinica, University of Florence, Florence, Italy; ${ }^{3} \mathrm{Center}$ for Research, High Education and Transfer DENOThe, University of Florence, Florence, Italy; ${ }^{4}$ Dipartimento di Medicina e Oncologia Sperimentali, University of Turin, Turin, Italy

Correspondence: Professor F Marra, Dipartimento di Medicina Interna, University of Florence, Viale Morgagni 85, Florence, I-50134, Italy.

E-mail: f.marra@dmi.unifi.it

${ }^{5}$ These two authors contributed equally to this work.

Received 7 November 2008; revised 28 July 2009; accepted 31 July 2009
} 
this context, the generation of reactive oxygen intermediates has a pivotal role in the induction of damage to the cellular membranes and DNA. ${ }^{9,10}$

No animal models of NASH fully reproduce the pathogenetic mechanisms and histological features observed in humans. However, administration of a methionine- and choline-deficient (MCD) diet to rodents has been shown to recapitulate most of the features of this disease. ${ }^{11,12}$ The MCD diet is high in sucrose and fat but lacks methionine and choline, two essential components for hepatic $\beta$-oxidation and very low-density lipoprotein production. As a result, animals develop severe pericentral steatosis and necroinflammation, mainly characterized by infiltration with mononuclear cells and polymorphonuclear neutrophils. In addition, mice fed an MCD diet show unequivocal evidence of increased oxidative stress, which is likely to be important in the progression from steatosis to steatohepatitis and the eventual appearance of liver fibrosis. ${ }^{13,14}$ Thus, the rodent MCD model is widely accepted to test agents that reduce inflammatory changes or oxidative stress in the liver, and their potential ability to prevent the progression of steatohepatitis to fibrosis.

Curcumin, the yellow pigment of the plant Curcuma longa (turmeric), is extensively used for food preparation and is a potent antioxidant and chemopreventive agent in vivo. ${ }^{15}$ Curcumin has been used in different models of acute and chronic liver injury associated with high levels of oxidative stress and inflammation, including alcohol-related or carbon tetrachloride-induced liver injury. ${ }^{16,17}$ However, only limited information is available on the possible effects of curcumin on the development and progression of nonalcoholic steatohepatitis. Recent studies have indicated that curcumin ameliorates the early stages of damage in experimental steatohepatitis, ${ }^{13}$ but the effects of curcumin on the fibrogenic progression and long-term outcome of this condition have not been tested so far. In this study, we provide evidence that administration of curcumin to mice fed an MCD diet reduces fibrotic scar formation and intrahepatic expression of fibrogenic genes. In addition, curcumin limits secretion of tissue inhibitor of metalloprotease (TIMP)-1 and generation of reactive oxygen species in cultured human hepatic stellate cells (HSCs).

\section{MATERIALS AND METHODS}

\section{Animals and Experimental Protocol}

Male C57BL/6 mice weighing between 20 and $25 \mathrm{~g}$ were purchased from Charles River Laboratories (Calco, Italy). All animals, 8 weeks of age at the beginning of the study, were housed six or seven per cage and kept under a controlled temperature of $22 \pm 2^{\circ} \mathrm{C}, 50-60 \%$ relative humidity and $12 \mathrm{~h}$ light/dark cycles. Mice had free access to food and water ad libitum and were weighed at weekly intervals throughout the experiment. Mice were fed either a diet deficient in methionine and choline (MCD diet) or the same diet supplemented with methionine and choline (control diet,
CD). Diets were prepared by Dottori Piccioni Laboratories (Milan, Italy) and stored at $4{ }^{\circ} \mathrm{C}$ until used. Experimental animals receiving the different diets were further subdivided to receive intraperitoneal administration of either curcumin or its vehicle (dimethylsulfoxide, DMSO), both purchased from Sigma Chemical (Saint Louis, MO, USA). Curcumin was dissolved in DMSO at a concentration of $0.1 \mathrm{mg} / \mathrm{ml}$, and $250 \mu \mathrm{l}$ of this solution (equal to $25 \mu \mathrm{g}$ of curcumin), or an equal volume of vehicle (DMSO), was administered intraperitoneally to the animals every other day. Solutions were made fresh before each administration. Six to eight animals in each of the four experimental groups (CD-DMSO, CDCurcumin, MCD-DMSO, MCD-Curcumin) were euthanized at 4,8 or 10 weeks by exsanguination under anesthesia with an i.p. injection of $80 \mathrm{mg} / \mathrm{kg} 50 \%$ tiletamine hydrochloride and 50\% zolazepam hydrochloride (Zoletil, Virbac, France). Body weight was recorded and blood was collected from the inferior vena cava, centrifuged, and serum stored for further analysis. Livers were rapidly dissected out, weighed, snap-frozen in liquid nitrogen and kept at $-80^{\circ} \mathrm{C}$ for RNA and protein extraction. A portion of the liver was immediately fixed in formalin for histological analyses. All animals received humane care, and experimental protocols were conducted according to established international guidelines (Guide for the Care and Use of Laboratory Animals, NIH publication No. 86-23) after approval by the National Regulatory Authorities.

\section{Serum Aminotransferase Levels}

Blood samples were centrifuged at 3000 r.p.m. for $10 \mathrm{~min}$ at $4^{\circ} \mathrm{C}$ to obtain serum, that was kept at $-20^{\circ} \mathrm{C}$ until analyzed. Serum alanine-amino transferase activity was determined using a commercially available kit (DiaSys Diagnostic Systems GmbH, Germany).

\section{Liver Histology}

A portion of liver tissue was fixed by immersion in $10 \%$ buffered formalin ( $\mathrm{pH}$ 7.4) for $24 \mathrm{~h}$. The fixed tissue was dehydrated in graded ethanol, paraffin-embedded and sectioned at a thickness of $4 \mu \mathrm{m}$. Hematoxylin-eosin and Sirius Red stainings were performed as previously described, ${ }^{18}$ and liver histology was evaluated by an experienced hepato-pathologist blinded to the type of treatment received by the animals. Necro-inflammation was graded focusing on zone 3 as 0 (absent), 1 (sparse or mild, focal), 2 (noticeable) and 3 (severe). Quantification of fibrosis and steatosis was performed by histomorphometric analysis using a digital camera (DFC 320, Leica, Germany) coupled to a bright field microscope (DM4000, Leica, Germany). Three randomly selected fields ( $\times 10$ magnification) of hematoxylin-eosin or picrosirius red-stained liver slides $(5-\mu \mathrm{m}$ sections) were scored in three sections of each animal at a final magnification of $\times 100$. Images were analyzed using the Image J $1.42 \mathrm{f}$ software (National Institute of Health, USA). Using the 'Image' tool window, images were prepared for analysis using 


\begin{abstract}
Table 1 List of the sets of FAM-labeled probes and primers (Applied Biosystems) for specific genes or for the housekeeping gene, GAPDH, used in real-time PCR assays
\end{abstract}

\begin{tabular}{ll} 
CD11b (Itgam) & Mm00434455-m1 \\
Monocyte chemoattractant protein-1 (MCP-1) & Mm00441242-m1 \\
Procollagen $\mid \alpha 1$ & Mm00801666-g1 \\
TNF & Mm00443258-m1 \\
TGF- $\beta 1$ & Mm00441724-m1 \\
Tissue inhibitor of metalloproteinase-1 (TIMP-1) & Mm99441818-m1 \\
Glyceraldehyde phosphate dehydrogenase (GAPDH) & Hs00171558-m1 \\
Human tissue inhibitor of metalloproteinase-1 & \\
(TIMP-1) & \\
Human glyceraldehyde phosphate dehydrogenase & $4326317 \mathrm{E}$ \\
(GAPDH) & \\
\hline
\end{tabular}

All assays were developed for murine genes, unless otherwise indicated.

the 'Adjust contrast' tool to optimize contrast and the 'Threshold' function to select specific signal. Results were measured in terms of $\%$ area occupied by specific staining.

\section{RNA Isolation and Quantitative PCR}

These experiments were carried out as previously described. ${ }^{19}$ The list of FAM-labeled probes and primers for specific genes or for the housekeeping gene, GAPDH, is indicated in Table 1. All reagents were purchased from Applied Biosystems (Foster City, CA, USA). Relative gene expression was calculated as $2^{-\Delta \mathrm{Ct}}\left(\Delta C_{\mathrm{t}}=C_{\mathrm{t}}\right.$ of the target gene minus $C_{\mathrm{t}}$ of GAPDH).

\section{Western Blot Analysis}

Liver tissue was homogenized in an Ultra-Turrax homogenizer in a lysis buffer containing Protease Inhibitor Cocktail (Sigma Chemical Co). Insoluble proteins were discarded by high-speed centrifugation at $4{ }^{\circ} \mathrm{C}$ at 12000 r.p.m. for $10 \mathrm{~min}$. Protein concentration was determined using the BCA Protein Assay kit according to the protocol provided by the manufacturer (Pierce Chemical, Rockford, IL, USA). Fifty micrograms of protein was separated by $10 \%$ SDS-PAGE and electroblotted on a polyvinylidene difluoride membrane (Millipore Corporation, Bedford, Massachussets, USA). After transfer, the membrane was stained with a Ponceau red solution (Sigma Chemical) to ensure equal protein loading. The staining was then removed by extensive washing in PBSTween. The membranes were then blocked with $2 \%$ BSA in $0.1 \%$ PBS-Tween and sequentially incubated with monoclonal anti- $\alpha$ smooth muscle actin antibodies (1:500 dilution, Sigma) in PBS-Tween containing 5\% nonfat milk. After extensive washing, the membranes were stained with horseradish peroxidase-conjugated antibodies against $\alpha$-SMA, and immunoreactive bands were detected using enhanced chemiluminescence (Amersham, Arlington Heights, IL, USA).

\section{Determination of Oxidative Stress in Liver Tissue} Intrahepatic levels of 8-hydroxy-2-deoxyguanosine (8-OHdG), a well-established marker of oxidative DNA damage, ${ }^{20}$ were determined by immunohistochemistry as described previously by Toyokuni et al. ${ }^{21}$ Morphometric assessment was performed using an optic microscope (Eclipse E600; Nikon, Tokyo, Japan) connected to a high-resolution camera (CC12 Soft-Imaging System, Münster, Germany).

\section{Measurement of Secretion of Tissue Inhibitor of Metalloproteinases- 1 by Cultured Stellate Cells}

Isolation, characterization and culture of human HSCs have been described in detail elsewhere. ${ }^{22}$ HSCs were used in their fully activated, myofibroblast-like phenotype. After overnight serum deprivation, the medium was changed to fresh serumfree medium and the cells were incubated in the presence or absence of curcumin for $24 \mathrm{~h}$. At the end of the incubation, cell-conditioned medium was collected and the levels of TIMP-1 measured by ELISA (Bender GmbH, Vienna, Austria).

\section{Detection of Intracellular Generation of Reactive Oxygen Species}

Human hepatic stellate cells were seeded in 12-well culture plates $\left(10^{5}\right.$ cells per well). After $24 \mathrm{~h}$ of incubation in serumfree medium, cells were preincubated for $30 \mathrm{~min}$ with $20 \mu \mathrm{M}$ curcumin and then left untreated or exposed for $15 \mathrm{~min}$ to the following pro-oxidant conditions: (a) $0.1 \mu \mathrm{M}$ 2-Methyl1,4-naphthoquinone (menadione); (b) $0.1 \mu \mathrm{M} \quad 2,3$-dimethoxy-1,4-naphthoquinone (DMNQ), to generate intracellularly superoxide anion or hydrogen peroxide; (c) treatment with the xanthine/xanthine oxidase system (hypoxanthine $0.4 \mathrm{mM}$-xanthine oxidase $2 \mathrm{mU}$ ), generating superoxide anion extracellularly. Intracellular generation of reactive oxygen species (ROS) was detected measuring the conversion of $2^{\prime}, 7^{\prime}$-dichlorodihydrofluorescein diacetate (DCF-DA, used at $5 \mu \mathrm{M}$ concentration), as recently described. ${ }^{23}$ Cells were observed and photographed under a Zeiss fluorescence microscope.

\section{Statistical Analysis}

Unless stated otherwise, data are expressed as mean \pm s.d. Comparisons of animals treated with or without curcumin were performed by Student's $t$-test. Histological scores of inflammation were compared using the Wilcoxon nonparametric test. $P$-values less than 0.05 were considered significant.

\section{RESULTS}

Administration of an MCD diet to mice, irrespective of supplementation with curcumin, caused a marked and progressive decrease in body weight and liver weight (Table 2). As a result, no differences in the liver/body weight ratio were recorded. Administration of curcumin did not result in major changes in body or liver weight at all time points tested $(4,8$ 
Table 2 Body and liver weight during the experimental protocol

\begin{tabular}{|c|c|c|c|c|}
\hline & Body weight T0 (g) & Body weight (g) & Liver weight (g) & Liver/body weight (\%) \\
\hline \multicolumn{5}{|l|}{4 weeks } \\
\hline CD-Curc & $27.0 \pm 1.6$ & $28.3 \pm 1.6$ & $1.083 \pm 0.342$ & $3.80 \pm 1.03$ \\
\hline MCD-DMSO & $24.2 \pm 1.2$ & $17.9 \pm 0.8$ & $0.742 \pm 0.106$ & $4.27 \pm 0.29$ \\
\hline \multicolumn{5}{|l|}{8 weeks } \\
\hline CD-DMSO & $23.3 \pm 1.7$ & $30.1 \pm 1.0$ & $1.080 \pm 0.139$ & $3.60 \pm 0.53$ \\
\hline CD-Curc & $24.8 \pm 0.5$ & $29.3 \pm 2.4$ & $0.863 \pm 0.113$ & $2.98 \pm 0.21$ \\
\hline MCD-DMSO & $23.9 \pm 1.0$ & $15.0 \pm 1.3^{*}$ & $0.428 \pm 0.227$ & $2.79 \pm 1.27$ \\
\hline CD-DMSO & $23.3 \pm 0.5$ & $27.2 \pm 1.5$ & $1.133 \pm 0.104$ & $4.16 \pm 0.28$ \\
\hline CD-Curc & $23.8 \pm 0.5$ & $28.8 \pm 2.3$ & $1.108 \pm 0.098$ & $3.85 \pm 0.28$ \\
\hline MCD-DMSO & $23.7 \pm 1.8$ & $14.1 \pm 1.2$ & $0.727 \pm 0.222$ & $5.19 \pm 1.68$ \\
\hline MCD-Curc & $23.5 \pm 1.0$ & $13.8 \pm 0.5$ & $0.624 \pm 0.032$ & $4.51 \pm 0.28$ \\
\hline
\end{tabular}

Mice were administered a methionine and choline-deficient diet (MCD) or an identical diet supplemented with methionine and choline (CD) and treated with curcumin (Curc.) or its vehicle (DMSO) for the indicated time points. At the beginning of the protocol (TO), and at the time of killing, body and liver weight were recorded. Data are mean \pm s.d. ${ }^{*}, P<0.05$ vs $M C D-C u r c$.

or 10 weeks), except for a significant reduction in body weight of mice receiving the MCD diet and curcumin for 8 weeks (Table 2). Liver injury was first assessed by measuring plasma ALT levels (Figure 1). On administration of CD, no significant changes in ALT were observed comparing mice receiving curcumin with those receiving DMSO. In contrast, administration of the MCD diet induced a 5-fold increase in ALT levels after 4 weeks of treatment. ALT remained elevated at 8 weeks, declining at 10 weeks of treatment (2.5-fold increase). In mice receiving curcumin, ALT levels were markedly and significantly reduced at the 4 -week time point in comparison with mice receiving DMSO (Figure 1). However, at later time points, the differences between mice receiving MCD-curcumin and MCD-DMSO were no longer evident.

To explore whether curcumin exerted beneficial effects on liver histopathology, paraffin-embedded specimens were first analyzed after staining with hematoxylin and eosin (Figure 2). MCD diet caused a rapid and marked accumulation of fat in hepatocytes, with a predominant macrovesicular pattern. As previously reported in this model, MCD diet also induced an evident infiltration with inflammatory cells, mostly represented by mononuclear cells, but with a contribution of polymorphonuclear leukocytes. Inflammation was detected in foci or in surrounding groups of hepatocytes with microvesicular steatosis, forming lipogranulomas (Figure 2). Steatosis and inflammation were

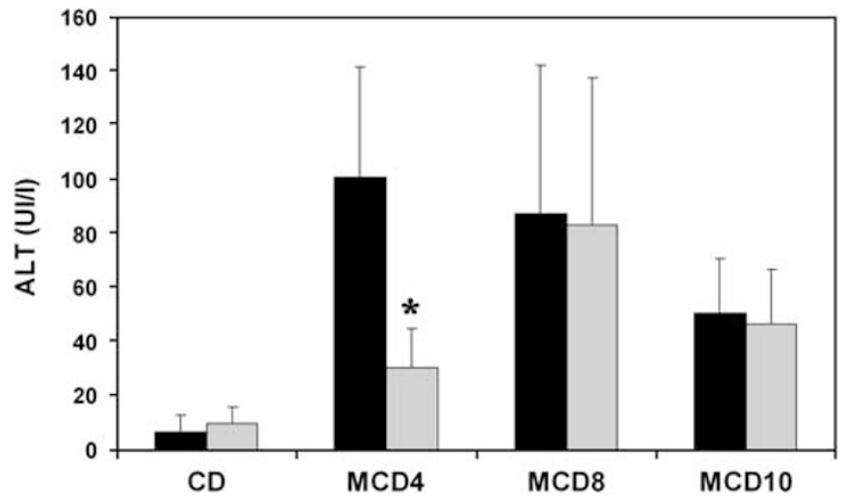

Figure 1 Curcumin reduces aminotransferase elevation at early time points during experimental steatohepatitis. Male C57/Bl6 mice were placed on a control diet (CD) or on a methionine and choline-deficient diet (MCD) for 4, 8 or 10 weeks, as indicated, and treated with DMSO (black columns) or with curcumin (gray columns). Serum alanine aminotransferase levels were assayed as described in Materials and Methods. Data are expressed as mean \pm s.d. ${ }^{*} P<0.05$ vs DMSO.

already present after 4 weeks of treatment and persisted throughout the study, with a moderate decline at later time points. Treatment with curcumin resulted in a general improvement of inflammation associated with the MCD diet. The effects of curcumin were more marked at later time points ( 8 and 10 weeks) when a significant decrease in the histological scores for necro-inflammation was observed 

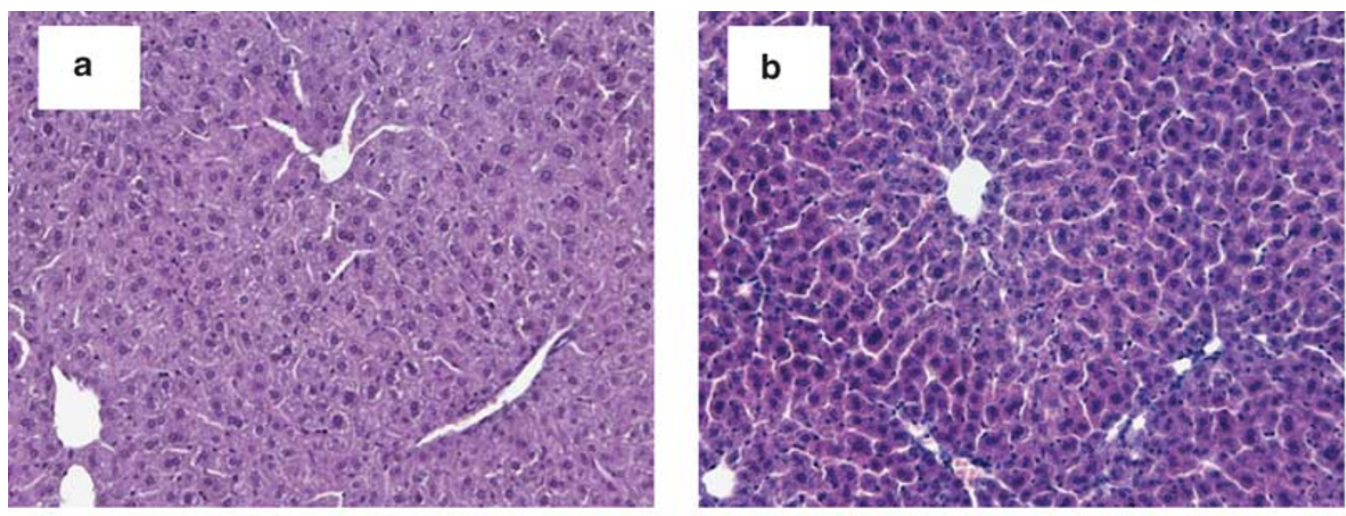

CD
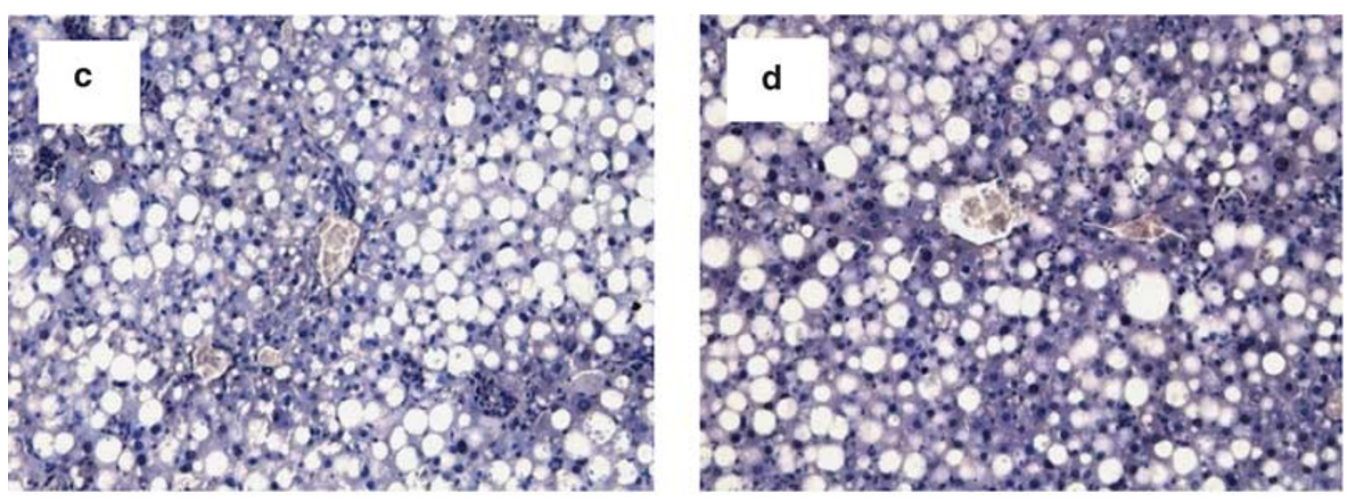

MCD

4 weeks
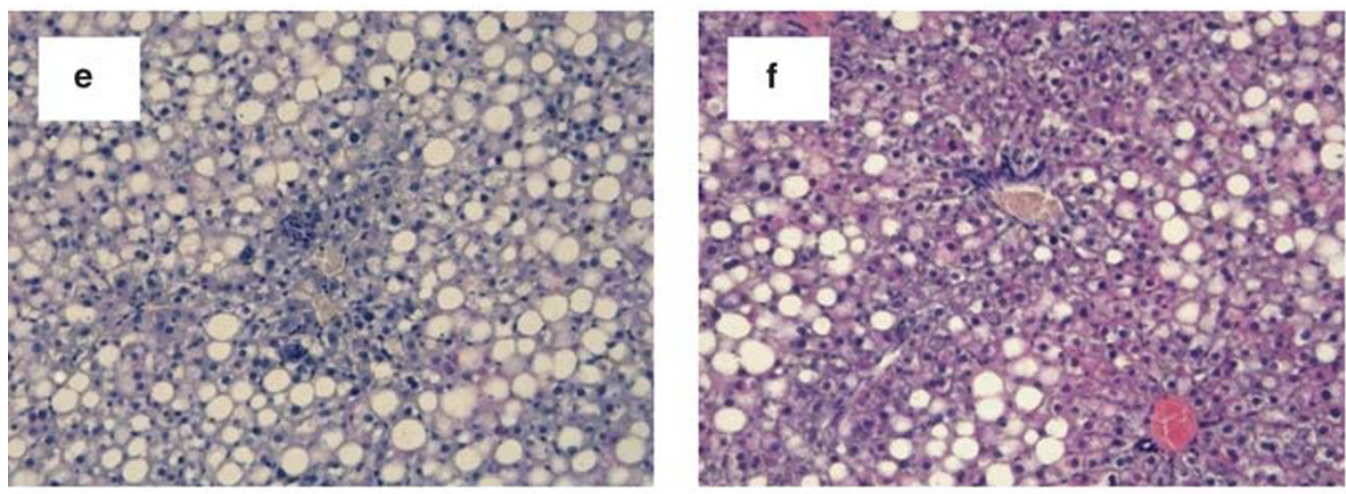

MCD

8 weeks

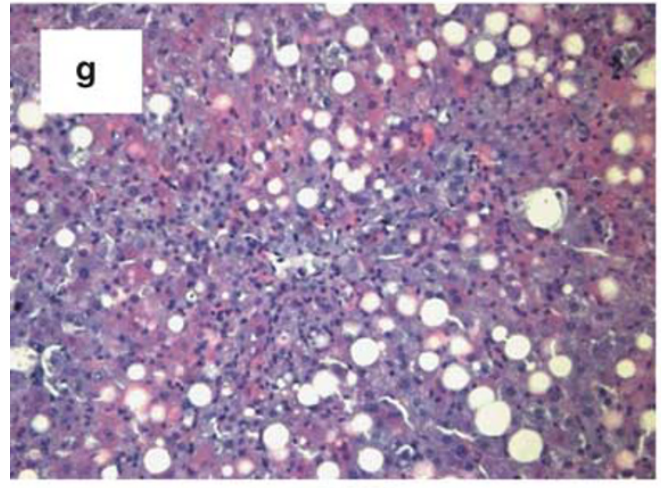

DMSO

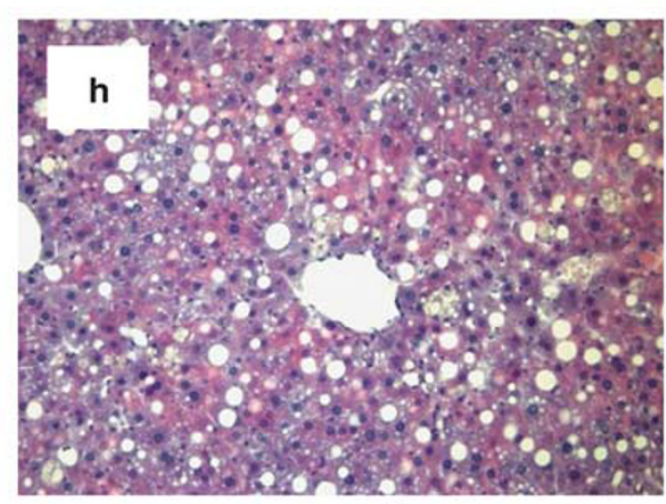

Curcumin
MCD

10 weeks

Figure 2 Effects of curcumin administration on liver histology during experimental steatohepatitis in mice. Male C57/BI6 mice were placed on a control diet $(C D, \mathbf{a}, \mathbf{b})$ or on a methionine and choline-deficient diet (MCD, c-h) for 4,8 or 10 weeks, as indicated, and treated with DMSO (a, c, e, g) or with curcumin $(\mathbf{b}, \mathbf{d}, \mathbf{f}, \mathbf{h})$. Liver histology was evaluated by hematoxylin and eosin staining. Original magnification, $\times 200$. 


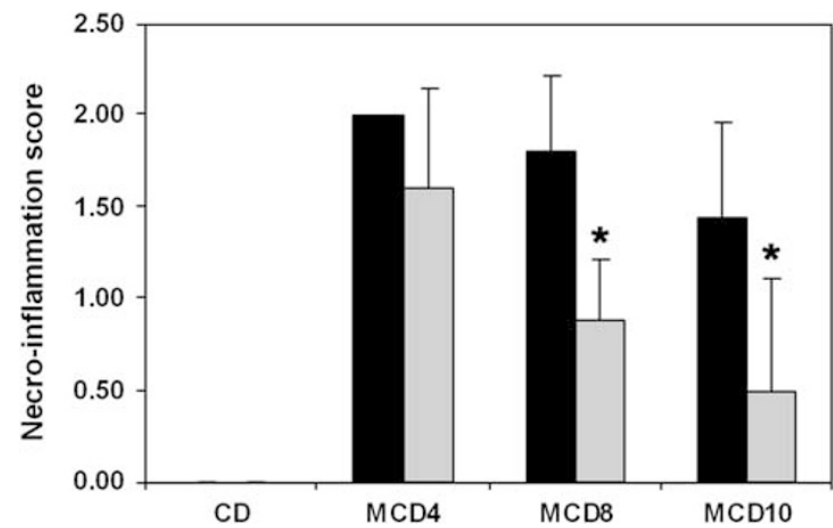

Figure 3 Effects of curcumin on the inflammatory scores. Histological analyses were conducted using light microscopy at $\times 100$ magnification. Slides as presented in Figure 2 were blindly evaluated by an expert in liver pathology, and a semiquantitative score was assigned as described in Materials and Methods for necro-inflammation. Scores in mice treated with DMSO (black columns) were compared with those in mice treated with curcumin (gray columns). Data are expressed as mean \pm s.d. ${ }^{\star} P<0.05$ vs DMSO.

(Figure 3). Curcumin resulted in a slight improvement in the grade of steatosis associated with the MCD diet, which, however, was not statistically significant when assessed by histomorphometry (data not shown). These data indicate that curcumin treatment induces a reduction of necro-inflammation in mice administered the MCD diet.

Although steatosis and inflammation appear early during the course of experimental steatohepatitis, fibrosis is a late event that has a deep impact on prognosis, causing hepatocellular dysfunction and the emergence of portal hypertension. We analyzed the appearance of fibrosis in mice receiving an MCD diet by staining liver specimens with Sirius red, which clearly detects collagen fibers (Figure 4). Fibrosis appeared after 8 weeks of MCD diet, surrounding the centrilobular vein and creating a fine network of fibers surrounding either individual cells or groups of hepatocytes in the perivenular area, in a chicken-wire manner. These features were more marked at 10 weeks of the study protocol. In contrast, little, if any, periportal fibrosis was observed (data not shown). After 10 weeks of diet, treatment with curcumin was accompanied by a marked and significant decrease in the accumulation of fibrillar extracellular matrix around the sinusoids and in the perivenular areas, as assessed by computerized histomorphometry (Figure 5 ).

Generation of oxidative stress-related molecules is a critical mechanism underlying the development and progression of nonalcoholic steatohepatitis, and is well reproducible in the MCD model. We used immunostaining to detect 8-OH-dG, a reliable marker of oxidative stress-mediated DNA damage. Although nuclei positive for $8-\mathrm{OH}-\mathrm{dG}$ were virtually absent in the livers of animals consuming the control diet, their abundance was markedly upregulated in mice administered the MCD diet (Figure 6). Curcumin, which also possesses antioxidant properties, led to a significant reduction in the percentage of nuclei positive for $8-\mathrm{OH}-\mathrm{dG}$, suggesting an inhibitory action on the generation of oxidative stress-related molecules.

We next investigated the molecular mechanisms implicated in the anti-inflammatory and anti-fibrogenic effects of curcumin, evaluating the intrahepatic expression of genes involved in the response to liver injury. Recruitment of inflammatory cells is critically dependent on the increased expression of chemokines, which attract different classes of leukocytes. As most of the inflammatory infiltrates in this model are represented by mononuclear cells, we analyzed the expression of monocyte chemoattractant protein-1 (MCP-1 or CCL2), which targets monocytes and T lymphocytes and is highly relevant in the response to hepatic injury. ${ }^{24} \mathrm{~A} 3$-fold increase in MCP-1 expression was observed in mice administered the MCD diet, whereas a significant reduction was present in animals treated with curcumin (Figure 7a). Similarly, expression of CD11b, a marker of leukocyte activation, was significantly reduced by treatment with curcumin (Figure $7 \mathrm{~b}$ ). We next analyzed the expression of genes related to fibrogenesis. Expression of type I procollagen, one of the most abundant components of the fibrillar extracellular matrix in fibrotic livers, was significantly reduced in mice administered curcumin while receiving an MCD diet (Figure 7c). As matrix accumulation depends not only on increased production but also on decreased removal, we analyzed the gene expression levels of TIMP-1, which inhibits the action of several matrix-degrading enzymes and has been tightly associated with the development of liver fibrosis. It is noted that the expression of TIMP-1 was more than 90-fold increased in mice administered the MCD diet, compared with CD (Figure 7d). Curcumin treatment reduced TIMP-1 expression by approximately $70 \%$ in comparison with untreated animals.

To provide further evidence for the antifibrogenic action of curcumin in this model, we analyzed the intrahepatic levels of $\alpha$-smooth muscle actin, a well-established marker of matrix-producing myofibroblasts, resulting mostly from the activation of HSCs. Expression of $\alpha$-smooth muscle actin was negligible in mice treated with the control diet, in keeping with the normal histological appearance of the tissue. After 10 weeks of treatment with the MCD diet, a marked upregulation of $\alpha$-smooth muscle actin expression was observed, in agreement with the increased deposition of fibrotic tissue and the related activation of HSCs (Figure 8). When analyzed by densitometry scanning, the expression of this marker was increased 20-fold in comparison with animals treated with the control diet. In contrast, animals receiving curcumin while eating an MCD diet showed a marked and significant reduction in $\alpha$-smooth muscle actin expression, which was found to be $80 \%$ lower than that in mice treated with DMSO. These data confirm that curcumin induces anti-fibrogenic actions, related at least in part to a lower accumulation of HSCs during the course of the fibrogenic process. 

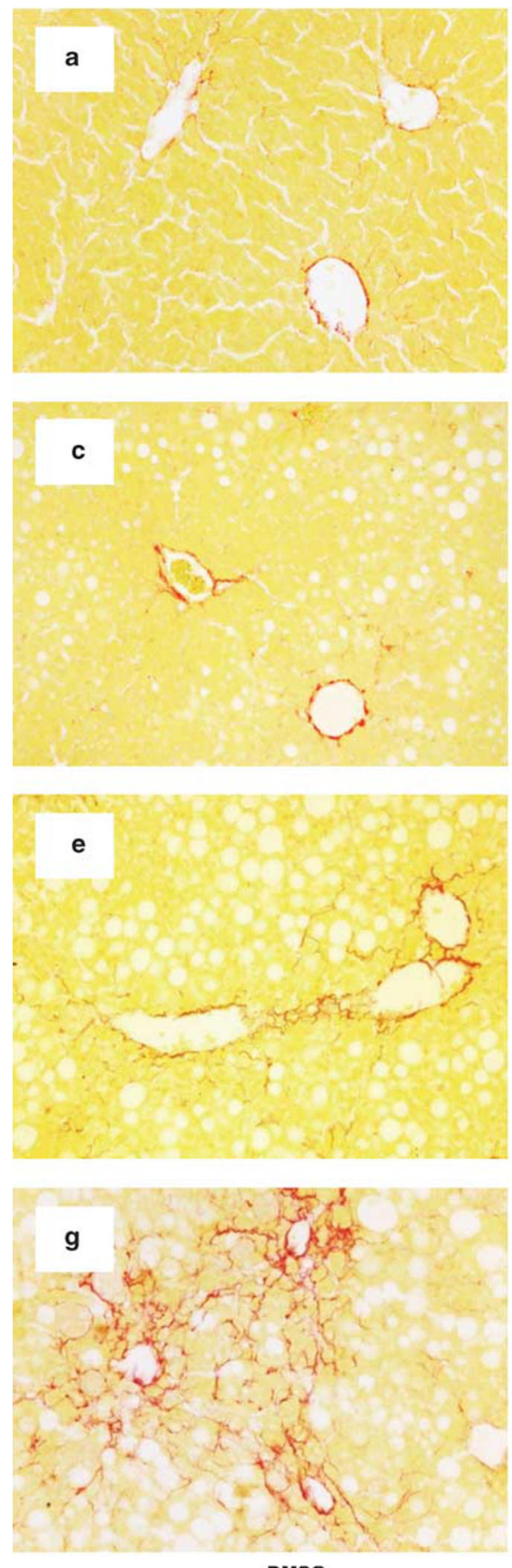

DMSO

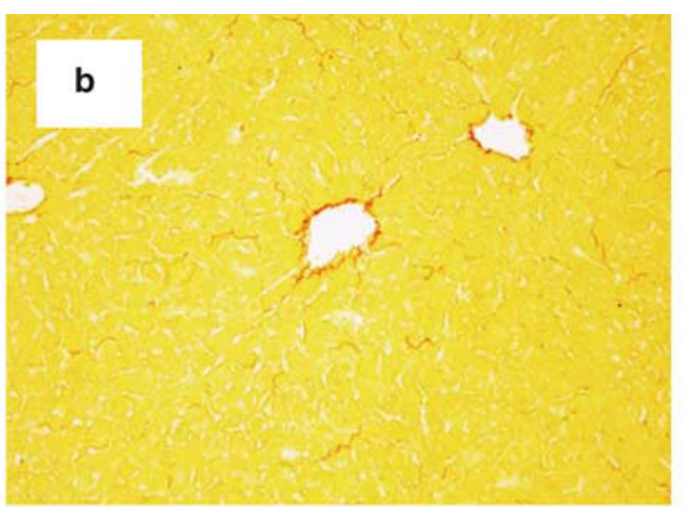

CD

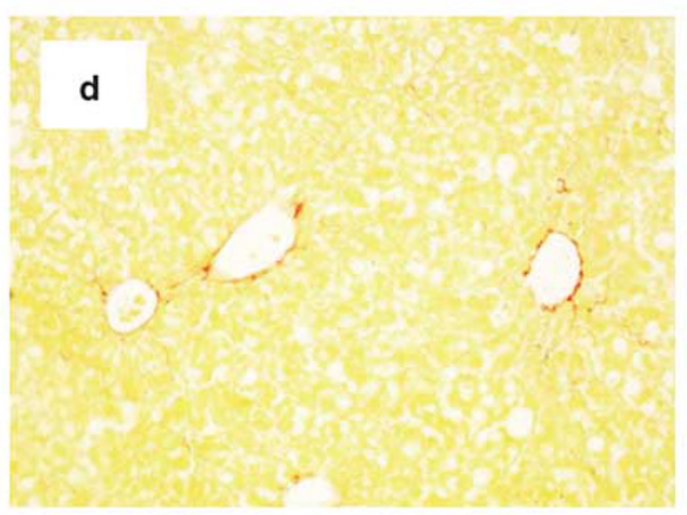

MCD

4 weeks

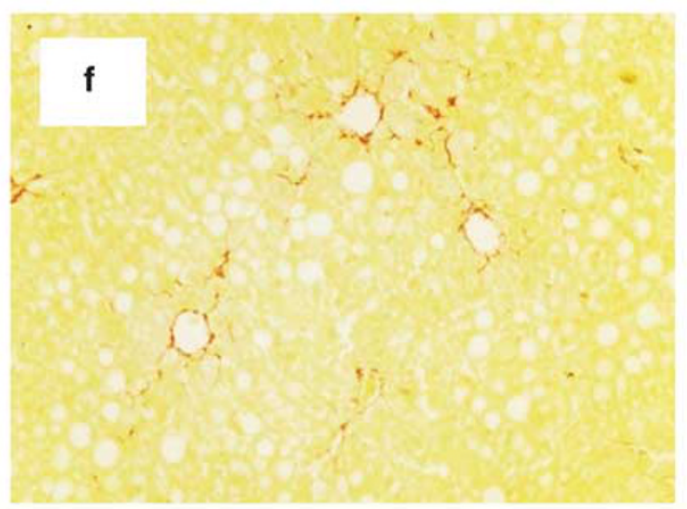

\section{MCD}

8 weeks

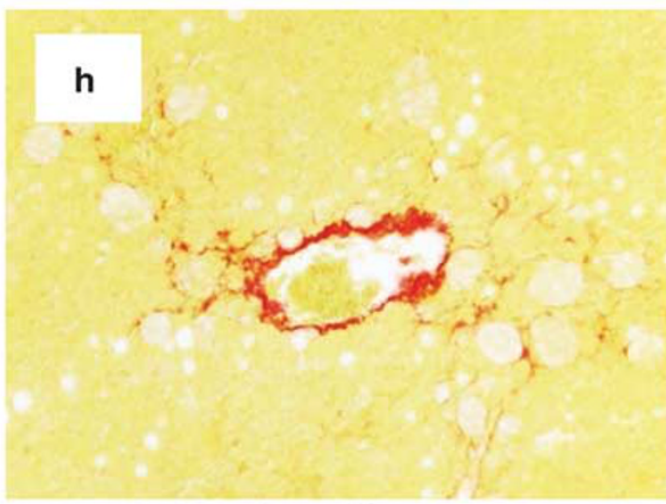

Curcumin

Figure 4 Effects of curcumin administration on hepatic fibrosis during experimental steatohepatitis in mice. Male C57/BI6 mice were placed on a control diet $(C D, \mathbf{a}, \mathbf{b})$ or on a methionine and choline-deficient diet (MCD, $\mathbf{c}-\mathbf{h})$ for 4,8 or 10 weeks, as indicated, and treated with DMSO (a, $\mathbf{c}, \mathbf{e}, \mathbf{g})$ or with curcumin $(\mathbf{b}, \mathbf{d}, \mathbf{f}, \mathbf{h})$. Hepatic fibrosis was evaluated by sirius red staining. Original magnification, $\times 200$. 


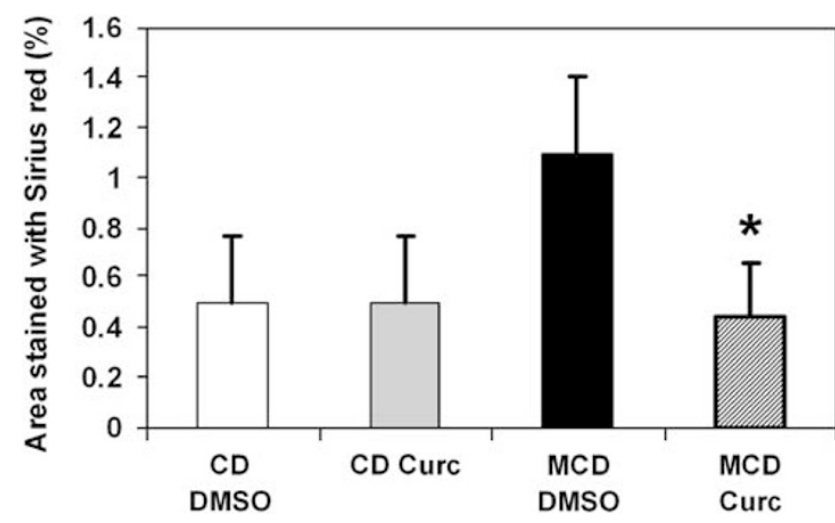

Figure 5 Effects of curcumin on histological fibrosis. Slides stained with Sirius red were evaluated by quantitative histomorphometry at 10 weeks, as described in Materials and Methods. Data of mice treated with DMSO (white and black columns) were compared with those of mice treated with curcumin (gray and cross-hatched columns). Data are expressed as mean \pm s.d. ${ }^{*} P<0.001$ vs MCD DMSO.

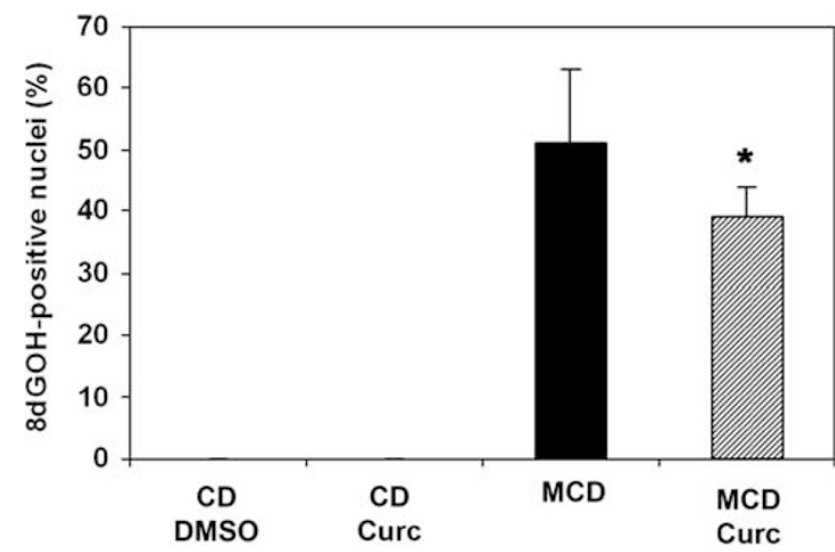

Figure 6 Curcumin reduces hepatic oxidative stress during experimental steatohepatitis. Mice (6-8 for each group) were placed on a control diet (CD) or on a methionine and choline-deficient diet (MCD) for 10 weeks. Data of mice treated with DMSO (white and black columns) were compared with those of mice treated with curcumin (gray and cross-hatched columns). Nuclei positive for 8 hydroxy-deoxyguanidine were immunostained and counted. Data are expressed as mean \pm s.d. ${ }^{\star} P<0.05$ vs DMSO.

Curcumin has been indicated as a powerful modulator of the biology of activated HSCs. On the basis of the observation that treatment with curcumin exerts a potent inhibitory action on the expression of TIMP-1, we next investigated whether curcumin could affect TIMP-1 in an in vitro system (Figure 9). Cultured human HSCs were exposed to different concentrations of curcumin for $24 \mathrm{~h}$, and accumulation of TIMP-1 in cell-conditioned medium was assayed by ELISA. Concentrations of curcumin previously shown to modulate the biology of different cell types ${ }^{25,26}$ resulted in a dose-dependent reduction of TIMP-1 secretion. Further increases in curcumin concentration did not result in more evident effects. Curcumin also reduced the mRNA levels for TIMP-1, measured by real-time PCR, although this effect did not reach statistical significance (data not shown). We next evaluated the effects of curcumin as a direct antioxidant for HSCs. Cells were loaded with the fluorescent dye, DCF-DA, which allows the detection of any significant increases in intracellular levels of ROS with high sensitivity. ${ }^{23}$ Preincubation with curcumin significantly blocked the generation of ROS induced by three different protocols (Figure 10). In addition, when HSCs were incubated with hypoxanthine-xanthine oxidase, a significant upregulation of TIMP-1 secretion was observed (Figure 11), indicating that a pro-oxidant environment regulates the release of TIMP-1. When HSCs were pre-incubated with curcumin, at a concentration effective in reducing oxidative stress (see Figure 10), TIMP-1 secretion was significantly decreased (Figure 11). Thus, curcumin reduces the ability to secrete an inhibitor of matrix degradation by HSCs, and limits the production and effects of ROS in these fibrogenic cells.

\section{DISCUSSION}

Considerable attention is being directed to the identification of novel therapeutic strategies for nonalcoholic steatohepatitis, considering the extremely high prevalence of this disease. In particular, therapies that limit hepatic injury and the related occurrence of inflammation and fibrosis would be particularly appealing for this condition. Curcumin, a yellow coloring ingredient of the spice turmeric, obtained from the rhizome of Curcuma longa, is extensively used for food preparation, and has been used in indigenous herbal medicine for the treatment of inflammatory and liver disorders. Curcumin has potent antioxidant, antiinflammatory, antimutagenic and anticarcinogenic properties. ${ }^{15}$ In addition, curcumin has been shown to delay the onset of lipid peroxidation, to ameliorate chemically induced oxidative stress, and to increase the expression of xenobiotic detoxifying enzymes. ${ }^{15}$ Previous studies have also highlighted the protective effects of curcumin toward several types of chemically induced hepatotoxicity, including damage induced by carbon tetrachloride and by experimental alcoholic liver disease, ${ }^{16,17}$ providing the rationale for its possible use in the context of nonalcoholic steatohepatitis. In this study, we provide evidence for the first time that administration of curcumin limits the long-term evolution of experimental steatohepatitis, improving fibrosis and downregulating different genes involved in the fibrogenic process. Occurrence and progression of steatohepatitis are critically dependent on the presence of hepatocellular damage, inflammation and oxidative stress. ${ }^{8}$ Remarkably, curcumin was able to beneficially affect all these components, although the effects showed some variability. Animals treated with curcumin had lower ALT levels, at least during the early stages of the disease, together with reduced inflammation, histological evidence of injury, and signs of oxidative stress. It is important to underline that these events are tightly interconnected during the response of the liver to injury. Recruitment of inflammatory cells, mainly orchestrated by proteins of the chemokine family, ${ }^{24}$ contributes to the 

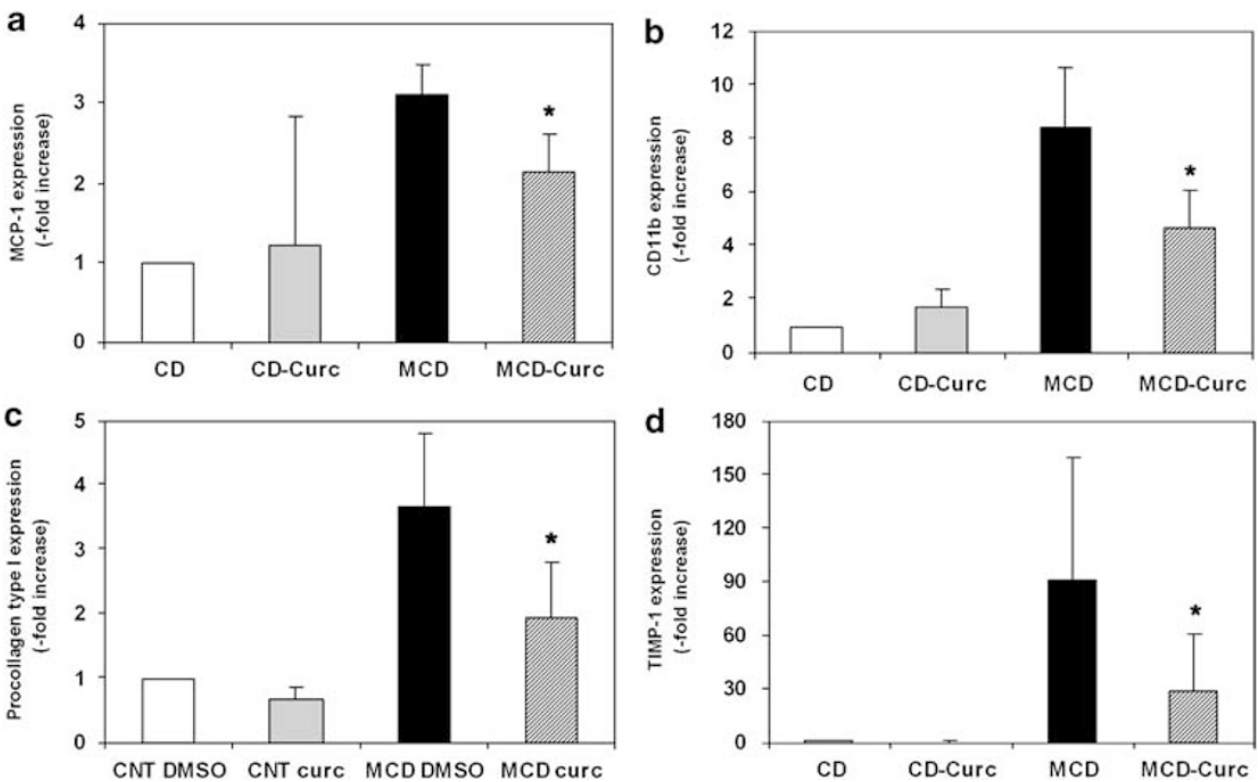

Figure 7 Effects of curcumin on hepatic gene expression during experimental steatohepatitis. Mice (6-8 for each group) were placed on a control diet (CD) or on a methionine and choline-deficient diet (MCD). At the time of the killing, liver tissue was collected for RNA extraction, and gene expression of monocyte chemoattractant protein-1 (4 weeks, panel a), CD11b (4 weeks, panel b), procollagen type I ( 8 weeks, panel c) and tissue inhibitor of metalloproteinase-1 (8 weeks, panel d) was measured by real-time PCR. Expression in mice treated with DMSO (white and black columns) was compared with that in mice treated with curcumin (gray and cross-hatched columns). Data are expressed as mean \pm s.d. ${ }^{\star} P<0.05$ vs DMSO.
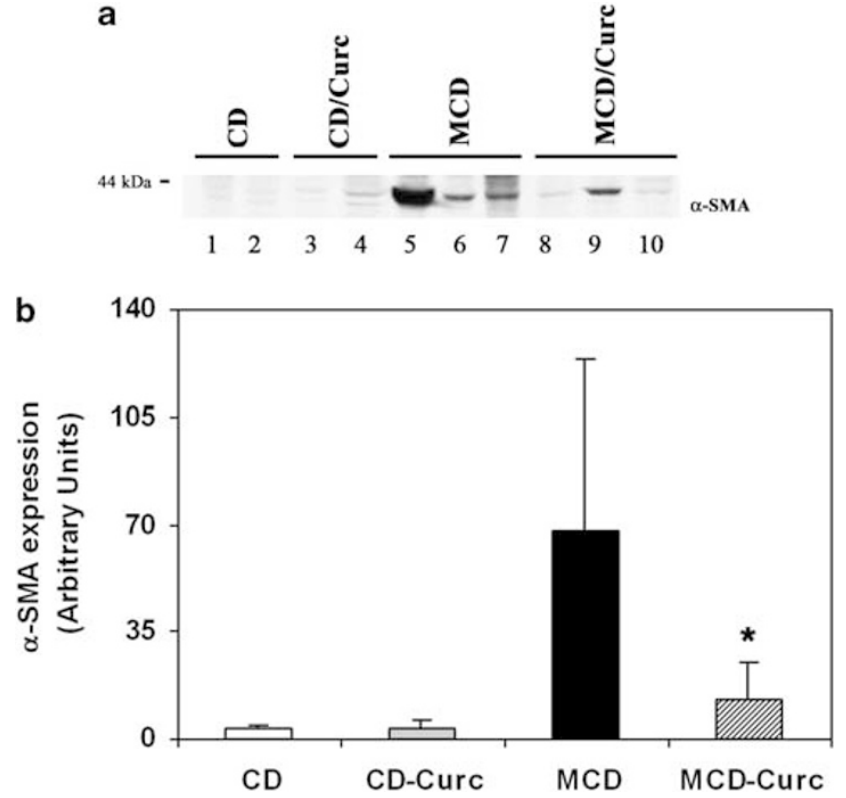

Figure 8 Reduced expression of $\alpha$-smooth muscle actin in mice treated with curcumin. Mice were placed on a control diet (CD) or on a methionine and choline-deficient diet (MCD) for 10 weeks. Liver tissue was homogenized and extracted for total protein. $\alpha$-SMA expression was analyzed by western blotting (panel a) as detailed in Materials and Methods. (b) Signal for $\alpha$-SMA was quantified by densitometry and expressed in barograms as mean \pm s.d. ${ }^{*} P<0.05$ vs DMSO. Data of mice treated with DMSO (white and black columns) were compared with those of mice treated with curcumin (gray and crosshatched columns).

exacerbation of hepatocyte damage and to the generation of oxidative stress-related products. These latter mediators, including reactive oxygen species and reactive aldehydes, can

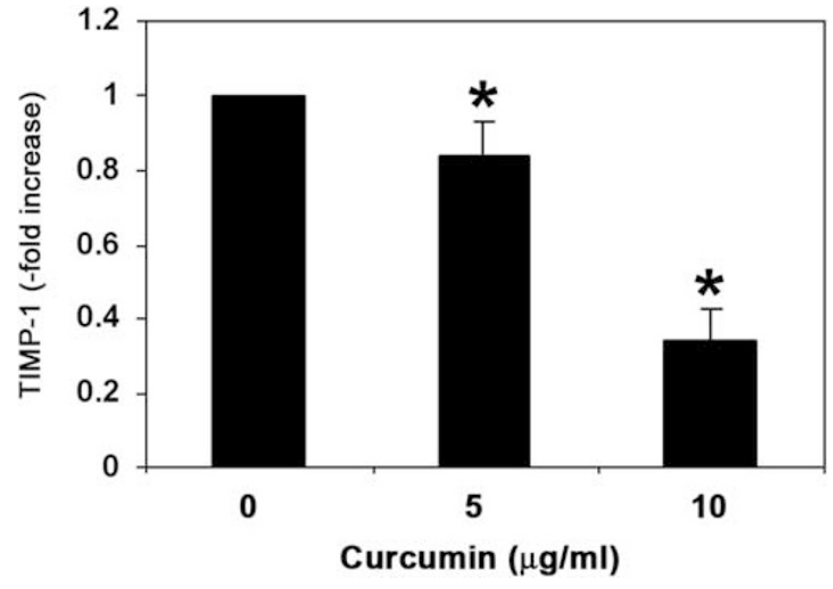

Figure 9 Curcumin inhibits the expression of TIMP-1 in cultured HSCs. Cultured human HSCs were deprived of serum and exposed to the indicated concentrations of curcumin for $24 \mathrm{~h}$. At the end of incubation, TIMP-1 concentrations were assayed by ELISA in cell-conditioned media. Mean \pm s.d. of three experiments. ${ }^{\star} P<0.05$ vs control.

trigger further inflammation and hepatocellular injury. Along these lines, this series of events may be interrupted, at least partially, in animals lacking inflammatory chemokines such as MCP-1, ${ }^{19}$ and curcumin was indeed effective in limiting the expression of this chemokine in animals exposed to the MCD diet. This effect was associated with a reduction in the amount of oxidative stress, measured as oxidative changes in hepatocyte DNA, and in the prevention of necro-inflammation. All these findings are in line with known activities of curcumin in the liver and in other tissues, where it has been previously shown to limit activation of the master 


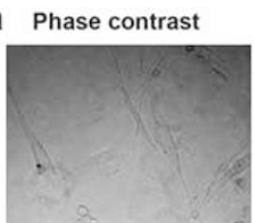

Control

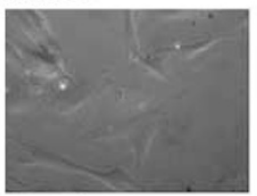

Menadione

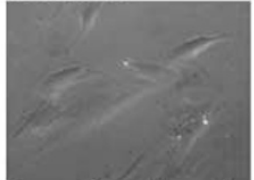

Curcumin + Menadione

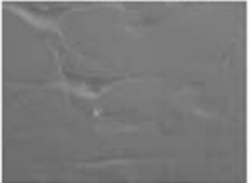

DMNQ

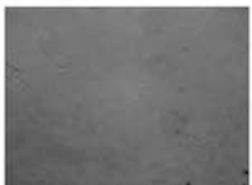

Curcumin + DMNQ

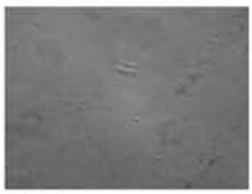

$\mathrm{X} / \mathrm{XO}$

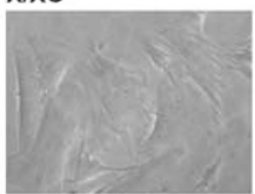

Curcumin $+\mathrm{X} / \mathrm{XO}$

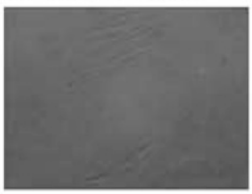

Curcumin
DCF-DA
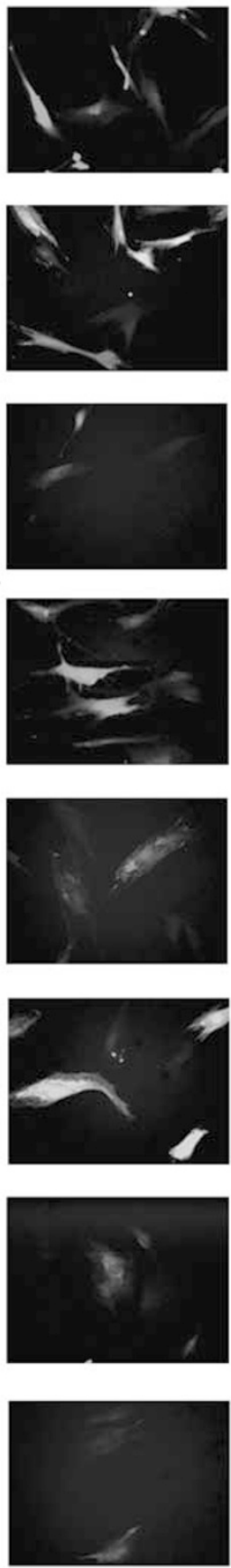

Overlay
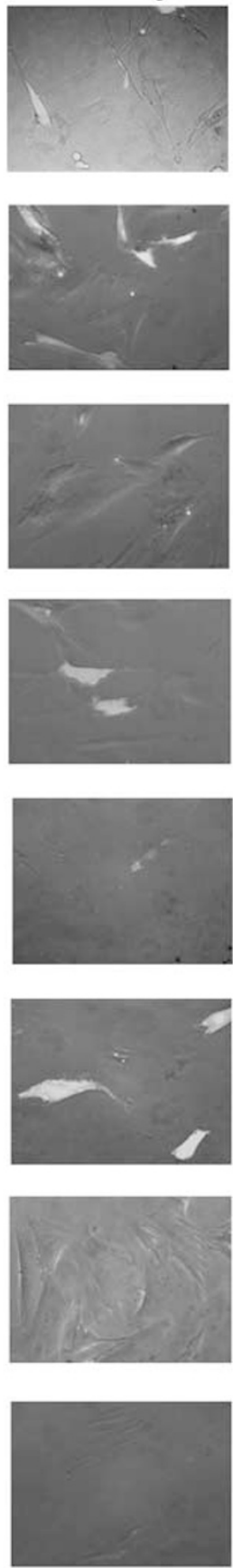

b

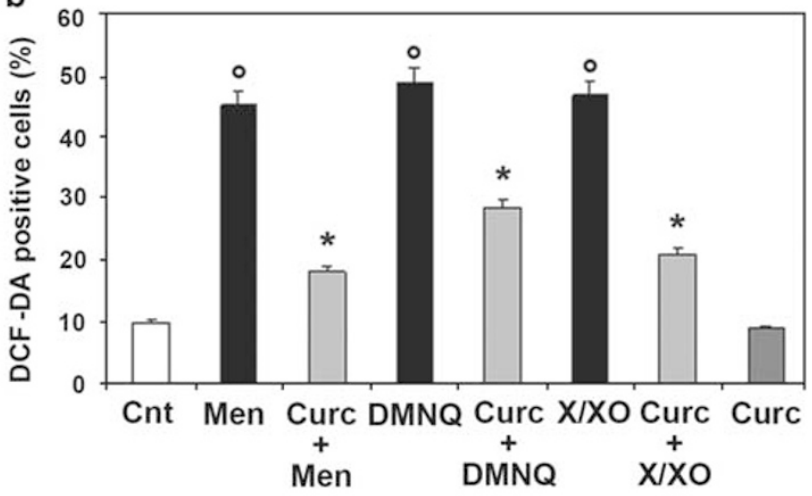

Figure 10 Reduced oxidative stress in HSCs treated with curcumin. Human HSCs were deprived of serum and either left untreated or preincubated with $20 \mu \mathrm{M}$ curcumin for $30 \mathrm{~min}$. At the end of incubation, cells were exposed for 15 min to $0.1 \mu \mathrm{M}$ 2-Methyl-1,4-naphthoquinone (Menadione), or $0.1 \mu \mathrm{M} 2,3-$ dimethoxy-1,4-naphthoquinone (DMNQ), or $0.4 \mathrm{mM}$ hypoxanthine-2 $\mathrm{mU}$ xanthine oxidase (X/XO). Intracellular generation of ROS was assessed by measuring the fluorescence of $2^{\prime}, 7^{\prime}$-dichlorodihydrofluorescein diacetate (DCF-DA, used at $5 \mu \mathrm{M}$ concentration) as described in Materials and Methods. Panel a: phase contrast photomicrographs (left row); fluorescence microscopy (central row); overlay (right row). Panel b: the percentage of cells positive for DCFDA fluorescence was counted in the different experimental conditions described above (mean \pm s.d. of three experiments). ${ }^{\circ} P<0.05$ vs control; ${ }^{\star} P<0.05$ vs the respective condition in the absence of curcumin.

inflammatory transcription factor, nuclear factor (NF) $-\kappa \mathrm{B}$ and to block oxidative injury. ${ }^{15}$ Our data are in clear agreement with the study of Leclercq et al, in which curcumin limited activation of NF- $\kappa \mathrm{B}$ and expression of MCP-1 and intercellular adhesion molecule-1, whereas steatosis was unaffected. ${ }^{13} \mathrm{NF}-\kappa \mathrm{B}$ activation has been previously shown to have a relevant role in the hepatic fibrogenic response. ${ }^{27}$ Recently, it has been reported that interruption of NF-kB 


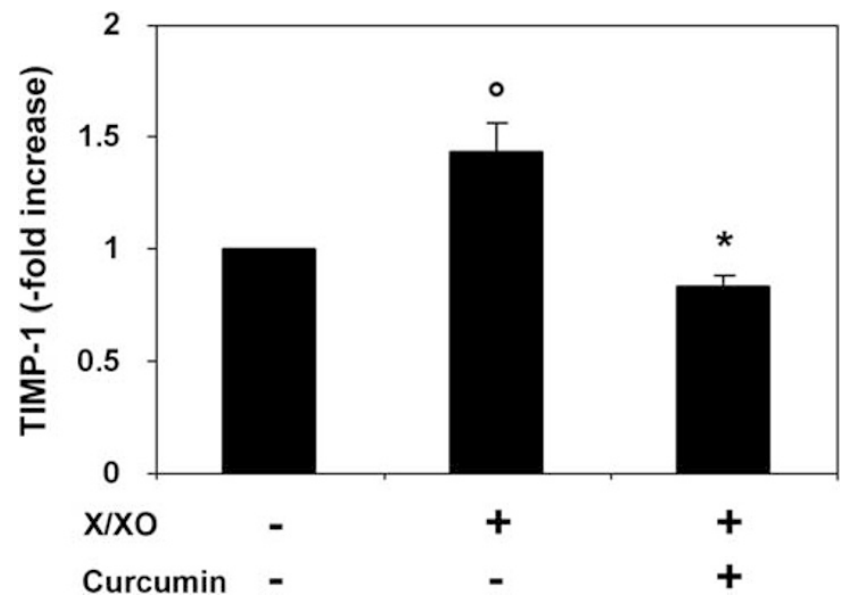

Figure 11 Upregulation of TIMP-1 secretion by oxidative stress is prevented by curcumin in HSCs. Human HSCs were deprived of serum and either left untreated or preincubated with $20 \mu \mathrm{M}$ curcumin for $30 \mathrm{~min}$, followed by exposure for $24 \mathrm{~h}$ to $0.4 \mathrm{mM}$ hypoxanthine- $2 \mathrm{mU}$ xanthine oxidase $(\mathrm{X} / \mathrm{XO})$. At the end of incubation, TIMP-1 concentrations were assayed by ELISA in cell-conditioned media (mean \pm s.d. of three experiments). ${ }^{\circ} P<0.05$ vs control; ${ }^{\star} P<0.05$ vs $\mathrm{X} / \mathrm{XO}$ in the absence of curcumin.

signaling by curcumin suppresses the expression of the profibrogenic cytokine, connective tissue growth factor, in HSCs. ${ }^{28}$ Therefore, further studies are needed to establish whether inhibition of NF- $\kappa$ B activation also has a role in the observed limitation of fibrosis in the MCD model. It is noted that Leclercq et al. did not report any effects on oxidative stress, ${ }^{13}$ whereas we did observe a protective effect of curcumin on DNA oxidation. The reason for this discrepancy is likely related to the longer time points investigated in the study reported herein. It should also be mentioned that we decided to administer curcumin through the intraperitoneal route, as in previously reported studies, ${ }^{29-31}$ to minimize possible differences in curcumin administration linked to the fact that the sickest animals on the MCD diet would have been likely to limit food intake.

The extended experimental protocol used in this study has allowed us to provide definitive evidence on the inhibitory effects of curcumin administration on the development of hepatic fibrosis in experimental steatohepatitis. Fibrogenesis is the common evolution of most forms of chronic liver disease, including nonalcoholic steatohepatitis, and is strictly linked to the eventual appearance of hepatic decompensation and death. The mechanisms of hepatic fibrogenesis have been the focus of extensive investigation over the last 15 years, ${ }^{32}$ and during steatohepatitis, inflammatory cell infiltration and generation of oxidative stress have been indicated as pivotal factors. ${ }^{8}$ Thus, reduced fibrogenesis observed in this study in animals treated with curcumin is dependent, at least in part, on the modulation of the pro-fibrogenic signals generated by inflammation and oxidative stress. However, several studies have indicated that curcumin has direct anti-fibrogenic effects through modulation of different aspects of the biology of HSCs, which on a process known as 'activation' acquire a phenotype of fibrogenic myofibroblasts and are critically involved in hepatic scarring. ${ }^{32}$ In particular, curcumin has been shown to induce expression of the transcription factor PPAR- $\gamma$, leading to inhibition of mitogen-stimulated proliferation of HSCs. ${ }^{33}$ In addition, curcumin blocked the activation of critical pro-fibrogenic pathways in rodent HSCs, including the activation of NF- $\kappa \mathrm{B}$ and extracellular signalregulated kinase, propagation of signal transduction downstream of TGF- $\beta$ receptors, and expression and signaling of PDGF- $\beta$ receptor and EGF receptor. ${ }^{33-35}$ These data indicate that curcumin may be a general inhibitor of fibrogenesis independent of the setting in which it develops. In this study, a direct effect on HSCs is suggested by the fact that expression of $\alpha$-smooth muscle actin, a classical marker of fibrogenic cells derived from the activation of HSCs, was significantly reduced in mice receiving curcumin, and was associated with reduced expression of type I procollagen. We also detected a striking decrease in the expression of TIMP-1 in the liver of mice administered curcumin together with an MCD diet, and the extent of reduction of TIMP-1 expression was more marked than that of type I procollagen. To provide further evidence for a direct action of curcumin on fibrogenic cells, we found that curcumin dosedependently inhibits the secretion of TIMP-1 by cultured HSCs, thus identifying an additional mechanism of reduced fibrogenesis. Further studies will be required to clarify the molecular mechanisms responsible for this effect, considering that we did not observe a significant reduction in the steadystate mRNA levels of TIMP-1 in HSCs exposed to curcumin. The modulatory effect of curcumin on inhibitors of metalloproteinases is in agreement with data recently reported in myofibroblasts from other tissues. ${ }^{36}$ On the other hand, curcumin has been shown to increase TIMP-1 expression in breast cancer cells, in which it provides anti-metastatic signals. ${ }^{37}$ It is noted that curcumin was also effective in reducing ROS generation by HSCs, and inhibited the increase in TIMP-1 secretion caused by oxidative stress, identifying additional mechanisms underlying the anti-fibrogenic action of this compound. ${ }^{10}$ Taken together, these data indicate that curcumin exerts its anti-fibrogenic action at multiple levels, including direct actions on HSCs.

It should be acknowledged that the use of the MCD diet as a model of steatohepatitis represents a limitation of our study, because it does not reproduce those metabolic derangements typical of patients with nonalcoholic steatohepatitis, including obesity and dyslipidemia. ${ }^{38}$ However, the principal aim of this study was to investigate the possible modulation of the progressive aspects of steatohepatitis, specifically fibrogenesis, that are very modestly induced in any animal model of the metabolic syndrome. ${ }^{12}$

In conclusion, we have shown that curcumin administration limits fibrosis development and progression in mice with experimental steatohepatitis. These data have particular relevance in a time where global demand for more affordable 
therapeutics and concerns about commonly used drugs are refocusing interest on traditional medicines, ${ }^{39}$ especially for the treatment of very prevalent diseases that are likely to require lengthy or lifelong treatments, such as nonalcoholic steatohepatitis.

\section{ACKNOWLEDGEMENT}

This study was supported by grants from the Italian Ministry of Research (to FM and M Par), the University of Florence (to FM), Regione Piemonte (to M Par.), and the Italian Liver Foundation (to FM and M Pinz.).

\section{DISCLOSURE/CONFLICT OF INTEREST}

The authors declare no conflict of interest

1. Lazo M, Clark JM. The epidemiology of nonalcoholic Fatty liver disease: a global perspective. Semin Liver Dis 2008;28:339-350.

2. Ekstedt M, Franzen LE, Mathiesen UL, et al. Long-term follow-up of patients with NAFLD and elevated liver enzymes. Hepatology 2006:44:865-873.

3. Matteoni CA, Younossi ZM, Gramlich T, et al. Nonalcoholic fatty liver disease: a spectrum of clinical and pathological severity. Gastroenterology 1999;116:1413-1419.

4. Teli MR, James OF, Burt AD, et al. The natural history of nonalcoholic fatty liver: a follow-up study. Hepatology 1995;22:1714-1719.

5. Yeh MM, Brunt EM. Pathology of nonalcoholic fatty liver disease. Am J Clin Pathol 2007;128:837-847.

6. Ludwig J, Viggiano TR, McGill DB, et al. Nonalcoholic steatohepatitis: Mayo Clinic experiences with a hitherto unnamed disease. Mayo Clin Proc 1980;55:434-438.

7. Choi CS, Savage DB, Kulkarni $A$, et al.. Suppression of diacylglycerol acyltransferase-2 (DGAT2), but not DGAT1, with antisense oligonucleotides reverses diet-induced hepatic steatosis and insulin resistance. J Biol Chem 27 May 2007.

8. Marra F, Gastaldelli A, Svegliati Baroni G, et al. Molecular basis and mechanisms of progression of non-alcoholic steatohepatitis. Trends Mol Med 2008;14:72-81.

9. Edmison J, McCullough AJ. Pathogenesis of non-alcoholic steatohepatitis: human data. Clin Liver Dis 2007;11:75-104 ix.

10. Parola M, Robino G. Oxidative stress-related molecules and liver fibrosis. J Hepatol 2001;35:297-306.

11. Koteish A, Diehl A. Animal models of steatosis. Sem Liv Dis 2001;21: 89-104.

12. London RM, George J. Pathogenesis of NASH: animal models. Clin Liver Dis 2007;11:55-74 viii.

13. Leclercq IA, Farrell GC, Sempoux C, dela Pena A, Horsmans Y. Curcumin inhibits NF-kappaB activation and reduces the severity of experimental steatohepatitis in mice. J Hepatol 2004:41:926-934.

14. Leclercq IA, Farrell GC, Field J, et al. CYP2E1 and CYP4A as microsomal catalysts of lipid peroxides in murine nonalcoholic steatohepatitis. J Clin Invest 2000;105:1067-1075.

15. Anand $\mathrm{P}$, Thomas SG, Kunnumakkara AB, et al. Biological activities of curcumin and its analogues (Congeners) made by man and Mother Nature. Biochem Pharmacol 2008; 76:1590-1611.

16. Fu $\mathrm{Y}$, Zheng $\mathrm{S}$, Lin J, et al. Curcumin protects the rat liver from $\mathrm{CCl}_{4}$ caused injury and fibrogenesis by attenuating oxidative stress and suppressing inflammation. Mol Pharmacol 2008;73:399-409.

17. Nanji AA, Jokelainen $K$, Tipoe $G L$, et al. Curcumin prevents alcoholinduced liver disease in rats by inhibiting the expression of NF-kappa B-dependent genes. Am J Physiol Gastrointest Liver Physiol 2003;284:G321-G327.

18. Bataller R, Schwabe RF, Choi YH, et al. NADPH oxidase signal transduces angiotensin II in hepatic stellate cells and is critical in hepatic fibrosis. J Clin Invest 2003;112:1383-1394.
19. Zamara E, Galastri S, Aleffi S, et al. Prevention of severe toxic liver injury and oxidative stress in MCP-1-deficient mice. J Hepatol 2007:46:230-238.

20. Halliwell $B$, Whiteman $M$. Measuring reactive species and oxidative damage in vivo and in cell culture: how should you do it and what do the results mean? Br J Pharmacol 2004;142:231-255.

21. Toyokuni S, Tanaka T, Hattori Y, et al. Quantitative immunohistochemical determination of 8-hydroxy-2'-deoxyguanosine by a monoclonal antibody N45.1: its application to ferric nitrilotriacetate-induced renal carcinogenesis model. Lab Invest 1997;76:365-374.

22. Caligiuri A, Bertolani C, Guerra CT, et al. Adenosine monophosphateactivated protein kinase modulates the activated phenotype of hepatic stellate cells. Hepatology 2008:47:668-676.

23. Cannito $S$, Novo E, Compagnone A, et al. Redox mechanisms switch on hypoxia-dependent epithelial-mesenchymal transition in cancer cells. Carcinogenesis 2008;29:2267-2278.

24. Marra F. Chemokines in liver inflammation and fibrosis. Front Biosci 2002;7:d1899-d1914.

25. Chen HW, Huang HC. Effect of curcumin on cell cycle progression and apoptosis in vascular smooth muscle cells. Br J Pharmacol 1998;124:1029-1040.

26. Cohly HH, Taylor A, Angel MF, et al. Effect of turmeric, turmerin and curcumin on H2O2-induced renal epithelial (LLC-PK1) cell injury. Free Radic Biol Med 1998;24:49-54.

27. Elsharkawy AM, Mann DA. Nuclear factor-kappaB and the hepatic inflammation-fibrosis-cancer axis. Hepatology 2007:46:590-597.

28. Chen A, Zheng S. Curcumin inhibits connective tissue growth factor gene expression in activated hepatic stellate cells in vitro by blocking NF-kappaB and ERK signalling. Br J Pharmacol 2008;153:557-567.

29. Gaedeke J, Noble NA, Border WA. Curcumin blocks fibrosis in anti-Thy 1 glomerulonephritis through up-regulation of heme oxygenase 1. Kidney Int 2005;68:2042-2049.

30. Poylin V, Fareed MU, O'Neal P, et al. The NF-kappaB inhibitor curcumin blocks sepsis-induced muscle proteolysis. Mediators Inflamm 2008;2008:317851.

31. Swarnakar S, Ganguly K, Kundu P, et al. Curcumin regulates expression and activity of matrix metalloproteinases 9 and 2 during prevention and healing of indomethacin-induced gastric ulcer. J Biol Chem 2005;280:9409-9415

32. Friedman SL. Mechanisms of hepatic fibrogenesis. Gastroenterology 2008;134:1655-1669.

33. Lin J, Chen A. Activation of peroxisome proliferator-activated receptorgamma by curcumin blocks the signaling pathways for PDGF and EGF in hepatic stellate cells. Lab Invest 2008;88:529-540.

34. Zheng S, Chen A. Disruption of transforming growth factor-beta signaling by curcumin induces gene expression of peroxisome proliferator-activated receptor-gamma in rat hepatic stellate cells. Am J Physiol Gastrointest Liver Physiol 2007;292:G113G123.

35. Zhou Y, Zheng $S$, Lin J, et al. The interruption of the PDGF and EGF signaling pathways by curcumin stimulates gene expression of PPARgamma in rat activated hepatic stellate cell in vitro. Lab Invest 2007:87:488-498.

36. Yasui $\mathrm{H}$, Andoh $\mathrm{A}$, Bamba $\mathrm{S}$, et al. Role of fibroblast growth factor-2 in the expression of matrix metalloproteinases and tissue inhibitors of metalloproteinases in human intestinal myofibroblasts. Digestion 2004;69:34-44.

37. Shao ZM, Shen ZZ, Liu CH, et al. Curcumin exerts multiple suppressive effects on human breast carcinoma cells. Int J Cancer 2002;98: 234-240.

38. Torres DM, Harrison SA. Diagnosis and therapy of nonalcoholic steatohepatitis. Gastroenterology 2008;134:1682-1698.

39. Singh S. From exotic spice to modern drug? Cell 2007;130: 765-768. 